LINDGREN, D. and K.-S. KANG (1997): Status number - a useful tool for tree breeding. Research Report of the Forest Genetic Research Institute of Korea 33, pp. 154-165.

LindGREN, D. and T. J. MulLin (1998): Relatedness and status number in seed orchard crops. Can. J. For. Res. 28: $276-283$.

Lindgren, D. and F. Prescher (2005): Optimal clone number for seed orchards with tested clones. Silvae Genetica 54: 80-92.

Lindgren, D., O. Rosvall and D. DanusevičIUs: Unequal deployment of clones to a seed orchard when candidates are related (submitted manuscript).

NIKKANEN, T. and S. RUOTSALAINEN (2000): Variation in flowering abundance and its impact on the genetic diversity of the seed crop in a Norway spruce seed orchard. Silva Fennica 34: 205-222.

OLSSON, T. (2001): Parameters, relationship and selection in Pines. Doctoral thesis. Swedish University of Agricultural Sciences, Umea, Silvestria 192, 27 p. (and 4 papers).
Olsson, T., D. LindGRen and B. Li (2001): Balancing genetic gain and relatedness in seed orchards. Silvae Genetica 50: 222-227.

Rosvall, O. (1999): Enhancing Gain from Long-Term Forest Tree Breeding while Conserving Genetic Diversity. Ph.D thesis. Acta Universitatis Agriculturae Sueciae. Silvestria 109.

Rosvall, O., G. Jansson, B. Andersson, T. Ericsson, B. Karlsson, J. Sonesson and L.-G. Stener (2001): Genetic gain from present and future seed orchards and clone mixtures. Rep. of the For. Res. Inst. of Sweden 1: 36-41. ISSN 1103-4580.

Wang Tongli, S. N. Aitken, J. H. Woods, K. R. Polssson and S. MAGNussen (2003): Effects of inbreeding on coastal Douglas fir growth and yield in operational plantations: a model-based approach. Theor. Appl. Genet. 108: 1162-1171.

Woods, J. H. and J. C. HEAman (1989): Effect of different inbreeding levels on filled seed production in Douglasfir. Can. J. For. Res. 19: 54-59.

ZoBel, B. and J. TALBERT (1984): Applied forest tree improvement. Wiley, Prospect Heights, Ill.

\title{
Crossability Between Wild (Malus sylvestris) and Cultivated (M. x domestica) Apples
}

\author{
By A. S. LARSEN ${ }^{1), *}$, M. JenseN ${ }^{2)}$ and E. D. KJÆR ${ }^{1)}$
}

(Received $25^{\text {th }}$ October 2006)

\begin{abstract}
Malus sylvestris, a native fruit tree of Europe, is believed to be threatened by hybridization with the omnipresent cultivated apple (Malus $\mathrm{x}$ domestica). In the present study a series of controlled crossings were carried out in order to establish whether $M$. sylvestris can hybridize with its near relative, $M$. x domestica. By looking at fruit set, seed production, germination percentages, and development of seedlings following inter- and intraspecific crossings, no indication of neither pre- nor postzygotic barriers to hybridization between the two species was found. This can have important implications for management of the genetic resources of $M$. sylvestris.
\end{abstract}

Key words: Malus sylvestris, Malus x domestica, crossability, hybridization, conservation.

\section{Introduction}

The European crab apple (Malus sylvestris (L.) Mill.) is an insect pollinated species native to most of conti-

1) Division for Forest Genetic Resources, Copenhagen University, Hørsholm Kongevej 11, DK-2970 Hørsholm, Denmark.

2) Department of Horticulture, Århus University, Kirstinebjergvej 10, DK-5792 Årslev.

*) Corresponding author: Phone: +45 353316 53, Fax: +45 3533 15 17. E-mail: ansl@life.ku.dk. nental Europe and the British Isles. Within its natural range, the species is considered threatened due to habitat modifications and hybridization with the cultivated apple (Malus $\mathrm{x}$ domestica Borkh.). The latter has been suggested due to the great ability for hybridization between species within the genus (KORBAN, 1986) but also due to the occurrence of morphologically intermediate phenotypes in nature (STEPHAN et al., 2003). The issue of hybridization has traditionally been studied by use of morphological characters - in particular pubescence. Ontogenetic and phenotypic variation however, is likely to hamper such studies. Therefore, these studies have recently been supplemented by molecular studies which demonstrate that it is still possible to find genetically authentic populations of $M$. sylvestris with only small traces of hybridization or introgression (COART et al., 2003; WAGNER et al., 2004; LARSEN et al., 2006). At least this is true for the more or less dense populations that have been included in the reported studies.

Despite the great interest in studying the occurrence of hybrids between the two species in nature, very little is known about the actual ability of the two species to hybridize. Thus, to the knowledge of the authors no published studies exist that quantify the crossability between the two species directly. In the present study, we therefore tested the hypothesis that $M$. sylvestris has 
preference for pollination by individuals of its own species compared to pollinations from $M . \times$ domestica. This was done by comparing interspecific crossings with $M$. sylvestris as female parent to intraspecific crossings within $M$. sylvestris. The reproductive success of such crossings was evaluated by fruit set, seed production, germination percentages and seedling development. Germination percentages and seedling development were registered in order to check for the occurrence of postzygotic barriers to hybridization and early stage differences in general fitness between the two types of offspring.

Ability to self-pollinate was not tested in the present study as a gametophytic self-incompatibility system has been found in the Rosaceae family (NETTANCOURT, 2001) and it has further been shown that selfing is a rare event in $M$. sylvestris under natural conditions (LARSEN and KJÆR, unpublished).

\section{Materials and Methods}

In the spring of 2005 eight graftings of wild apples (produced autumn 2000) deriving from five locations in southern Denmark, were selected along with the five M. x domestica cultivars 'Elstar', 'Ingrid Marie', 'Discovery', 'Ildrød Pigeon' and, 'Rød Aroma' (all diploid). Wild accessions were determined to be $M$. sylvestris genotypes according to morphological characters (eg. WAGNER, 1996). All accessions were obtained from Århus University (Department of horticulture). Emasculated flowers of the $M$. sylvestris graftings were treated with a pollen mix from the five $M$. x domestica clones and a pollen mix from the five most heavily flowering graftings of $M$. sylvestris. An untreated control was included in order to test the consistency of the method. For each grafting, each of the three treatments was carried out on one panicle by selecting $3-5$ flowers in the balloon stage. Flowers were treated only once. After pollination, each panicle was isolated using transparent pollination bags (Cryovac, SM 750 super micro). In order to ensure full development of fruits deriving from controlled crossing, the remaining fruits were removed. Abscission of fruits during development was recorded along with the number of seeds per fruit at maturity. Pollination and tree cultivation was performed in a plastic tunnel greenhouse at Århus University.

Differences in the number of fruits developed per treatment were analyzed assuming a binomial distribution of the fruit set data (ie. the probability $p_{\mathrm{sxd}}$ and $p_{\mathrm{sxs}}$ for success after inter- and intraspecific crossings respectively). The null-hypothesis of similar fruit set after the two treatments were tested using the z-test (SOKAL and RoLF, 1981).

Germination was tested using 85 seeds from the intraspecific crossings and 139 from the interspecific crossings. Seeds were placed on moist vermiculite in closed plastic containers in the autumn of 2005 . The test was carried out at $5^{\circ} \mathrm{C}$ and the medium was kept moist by spraying. Germination was defined as the radicle's penetration of testa. Seeds started to germinate after 14 weeks. After 18 weeks, approx. two thirds of the seeds had germinated and the containers were transferred to a frost-free greenhouse with varying day temperatures of up to $20^{\circ} \mathrm{C}$. Progression of the germination was recorded weekly. After 20 weeks, the trial was terminated by recording the number of dead seeds along with an assessment of seedling development.

Table 1. - Fruit set data. For each M. sylvestris clone is shown the number of flowers pollinated with $M$. x domestica (syl x dom) and $M$. sylvestris (syl x syl) pollen respectively along with the resultant number of fruits and seeds developed. For each clone is also shown the average number of seeds per fruit. The bottom line indicates total numbers for each treatment along with percentage of successful pollinations. Total for seeds per fruit is calculated as the average over clones.

\begin{tabular}{|c|c|c|c|c|c|c|}
\hline Clone & Cross & $\begin{array}{l}\text { Hlowers } \\
\text { pollinated }\end{array}$ & $\begin{array}{c}\text { Fruits after } 4 \\
\text { weeks }\end{array}$ & $\begin{array}{l}\text { Mature } \\
\text { fruits }\end{array}$ & Seeds & $\begin{array}{l}\text { Seeds per } \\
\text { fruit }\end{array}$ \\
\hline \multirow{2}{*}{1} & syl $\times$ dom & 4 & 1 & 1 & 9 & 9.0 \\
\hline & $s y 1 \times s y l$ & 5 & 1 & 1 & 8 & 8.0 \\
\hline \multirow{2}{*}{2} & syl $\times$ dom & 3 & 2 & 2 & 16 & 80 \\
\hline & $s y 1 \times s y l$ & 4 & 0 & 0 & - & - \\
\hline \multirow{2}{*}{3} & syl $\times$ dom & 4 & 1 & 1 & 10 & 10.0 \\
\hline & syl $\times$ syl & 3 & 0 & 0 & - & - \\
\hline \multirow{2}{*}{4} & syl $\times$ dom & 4 & 0 & 0 & $=$ & - \\
\hline & syl $\times$ syl & 4 & 0 & 0 & - & - \\
\hline \multirow{2}{*}{5} & syl $\times$ dom & 4 & 4 & 3 & 28 & 9.3 \\
\hline & syl $\times s y l$ & 4 & 3 & 1 & 10 & 10.0 \\
\hline \multirow{2}{*}{6} & sy] $\times$ dom & 3 & 2 & 2 & 17 & 8.5 \\
\hline & syl $\times$ syl & 4 & 3 & 3 & $2 \mathrm{l}$ & 7.0 \\
\hline \multirow{2}{*}{7} & syl $\times$ dom & 4 & 4 & 4 & 32 & 80 \\
\hline & syl $\times$ syl & 3 & 3 & 3 & 28 & 9.3 \\
\hline \multirow{2}{*}{8} & syl $x$ dom & 4 & 4 & 4 & 27 & 6.8 \\
\hline & syl $\times$ syl & 4 & 4 & 4 & 18 & 4.5 \\
\hline \multirow{2}{*}{ Total } & syl $\times$ dom & 30 & $18(60 \%)^{4}$ & $17(57 \%)^{4}$ & 139 & $8.5^{a 1}$ \\
\hline & syl $\times$ syl & 31 & $14(45 \%)^{a}$ & $12(39 \%)^{\mathrm{h}}$ & 85 & $7.8^{\mathrm{n}}$ \\
\hline
\end{tabular}

Note: Observed numbers with the same letter are not significantly different at the $5 \%$ level. 


\section{Results and Discussion}

In the pollination trial, seven of the eight $M$. sylvestris clones set fruit. Five set fruit following both intra- and interspecific crossings, while 2 of them only set fruit following the interspecific crossings. The difference in fruit set (percentage of successful pollinations) at maturity was found slightly significant $(P<5 \%)$ whereas difference in fruit set registered one month after pollination was non-significant (Table 1). The difference in fruit set at the two points was caused by the abscission of three fruits all deriving from the same mother clone (Table 1).

In general, fruit set following artificial pollinations was relatively low. This could be due to the fact that the styles were not fully receptive at the stage of pollination which was carried out immediately after emasculation. The average number of fully developed seeds per fruit was found to be slightly higher in inter- than intraspecific crossings. However, $t$-test of the null-hypothesis of no difference could not be rejected.

In the germination test only two of the harvested seeds did not germinate. These were both infected by fungi. The rest of the seeds germinated, and all seedlings developed normally according to the ISTA rules for seed testing (InTERnational SEED Testing Association, 1999) - i.e. normal development of the first primary leaves.

When compared within the five clones for which seeds from both crossings were available, there was a tendency towards interspecific crossings germinating earlier than intraspecific crossings (Figure 1). Timing of germination is a parameter of potential importance to fitness under natural conditions, because too early germination can result in frost damage and late germination may result in poor competitive ability. Still, in the present case the observed differences between the hybrids and the wild species were not large (about 1 week, cf. Figure 1). Some variation was also observed between clones. It was noted that germination ceased temporarily upon transfer of the seedlings (and ungerminated seed) to the greenhouse in week no. 4 (cf. Figure 1).

In our study, we did not offer pollen of both species in mixture, and we can therefore not exclude the possibility that pre-zygotic pollen competition (e.g. due to factors such as different pollen tube growth) can reduce the degree of hybridization when pollination takes place under conditions where pollen of both species is abundant (e.g. discussed for Quercus by BoAviDA et al., 2001). Still, our results show that there are no genetic hindrances to hybridization between the two studied species at either the pre- or postzygotic level.

As a consequence, we must expect that substantial hybridization between the two species will occur given the time of flowering overlap and the geographical distance between them is not too great. This has serious implications for the conservation of $M$. sylvestris in the Danish landscape. Thus, in the phase of selecting populations for in situ conservation networks (cf. GRAUDAL et $a l ., 1995)$, one should look for populations that have historically been geographically isolated from $M$. x domesti$c a$. Where such information is not available, it is recommended to perform an investigation by morphological and/or molecular means in order to establish the hybridization status of the candidate populations (cf. COART et al., 2003; LARSEN et al., 2006). However, the observed high degree of crossability, combined with apparently relatively few hybrids occurring in at least some of the Danish populations, indicates that other types of reproductive barriers must provide some protec-
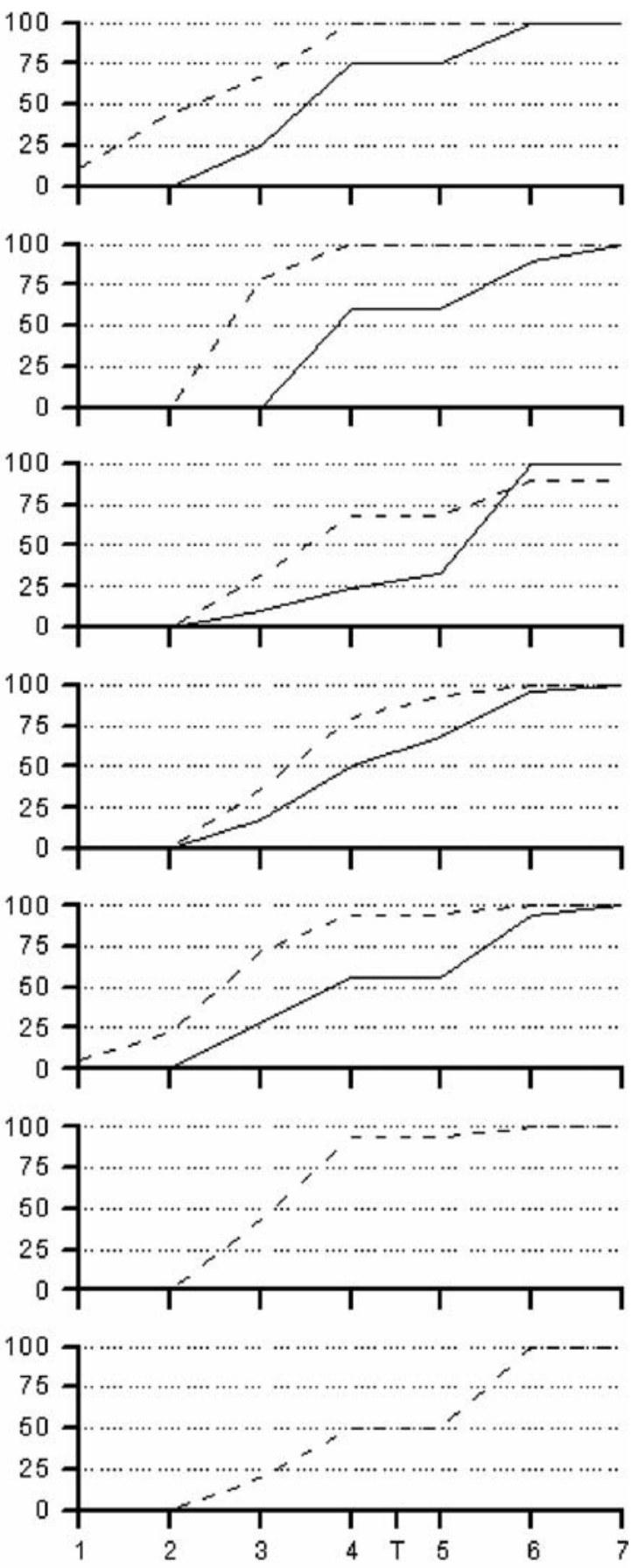

Week no.

Figure 1. - Development in germination percentage during the period of observation. Week no. 1 refers to the onset of germination which occured 14 weeks after sowing the seeds. Dashed lines represent interspecific crossings between $M . \mathrm{x}$ domestica and $M$. sylvestris; solid lines represent intraspecific crossings in $M$. sylvestris. T denotes the time of transplantation from the cold store to the green house. 
tion against hybridization. Under Danish conditions it has been suggested that isolation by distance is one of the primary mechanisms hindering hybridization in natural populations. This is because of the predominance of short distance pollination events in natural populations (LARSEN and KJÆR, unpublished). In addition, differences in flowering phenology between the two species ('isolation in time') are also thought to play a role (LARSEN et al., 2006).

Our result is also of importance for propagation of $M$. sylvestris for planting purposes. There should be a suitable isolation distance between a given $M$. sylvestris seed orchard and the (major) occurrences of $M . \mathrm{x}$ domestica. Honey- and bumblebees (both major pollinators of $M$. sylvestris) are observed to have median foraging distances of several kilometers over a range of landscape types (Osborne et al., 1999; BEEKMAN and RATNIEKS, 2000; StefFan-Dewenter and KuHN, 2003). Although such long distance pollination events might be of importance in an evolutionary context (ELLSTRAND, 2003), it is questionable whether they are of practical importance in seed orchards of $M$. sylvestris. Pollinator behavior in a relatively dense seed orchard further speaks in favor of shorter isolation distances. Thus, for Prunus mahaleb L. GARCIA et al. (2005) found that pollination distances were shorter and the number of effective fathers lower in dense stands than in more open stands. This was found both in relation to conspecifics and in general. A likely explanation for this could be the generalist behavior of the pollinators, meaning that they will not move far if ample sources of pollen are available in the near neighborhood (CRESSWELL, 1997).

\section{References}

Beekman, M. and F. L. W. Ratnieks (2000): Long range foraging by the honey-bee, Apis mellifera L, Funct. Ecol. 14, 490-496.

Boavida, L. C., J. P. Silva and J. A. FeiJó (2001): Sexual reproduction in the cork oak (Quercus suber L). II. Crossing intra- and interspecific barriers. Sex. Plant Reprod. 14, 143-152.

Coart, E., X. Vekemans, M. J. M. Smulders, I. Wagner, J. Huylenbroeck, E. Bockstaele and I. Roldán-Ruiz (2003): Genetic variation in the endangered wild apple (Malus sylvestris (L.) Mill.) in Belgium as revealed by amplified fragment length polymorphism and microsatellite markers, Mol. Ecol. 12, 845-857.
CResswell, J. E. (1997): Spatial heterogeneity, pollinator behaviour and pollinator-mediated gene flow: bumblebee movements in variously aggregated rows of oil-seed rape, Oikos 78, 546-556.

Ellstrand, N. C. (2003): Current knowledge of gene flow in plants: implications for transgene flow, Philos. Trans. R. Soc. Lond. B Biol. Sci. 358, 1163-1170.

Garcia, C., J. M. Arroyo, J. A. Godoy and P. Jordano (2005): Mating patterns, pollen dispersal, and the ecological maternal neighbourhood in a Prunus mahaleb L. population, Mol. Ecol. 14, 1821-1830.

Graudal, L., E. D. KJÆR and S. CANGER (1995): A systematic approach to conservation of genetic resources of trees and shrubs in Denmark. For. Ecol. Manage. 73, $117-134$.

International Seed Testing Association (1999): International rules for seed testing, Seed Sci. Technol., 27.

Korban, S. S. (1986): Interspecific hybridization in Malus. Hortscience 21, 41-48.

Larsen, A. S., C. B. Asmussen, D. C. Olrik, E. Coart and E. D. KJÆR (2006): Hybridization and genetic variation in Danish populations of European crab apple (Malus sylvestris), Tree Genet. Genom. 2, 86-97.

NETTANCOURT, D. (2001): Incompatibility and incongruity in wild and cultivated plants, 2 edn, Springer, Berlin.

Osborne, J. L., S. J. Clark, R. J. Morris, I. H. Williams, J. R. Riley, A. D. Smith, D. R. Reynolds and A. S. EDWARDS (1999): A landscape-scale study of bumble bee foraging range and constancy, using harmonic radar, J. Appl. Ecol. 36, 519-533.

SoKAL, R. R. and J. F. RoHLF (1981): Biometry: the principles and practice of statistics in biological research. $2^{\text {nd }}$ ed., W. H. Freeman and Company, San Francisco, 859p.

StefFan-Dewenter, I. and A. KunN (2003): Honeybee foraging in differentially structured landscapes, Proc. R. Soc. Lond. B Biol. Sci. 270, 569-575.

Stephan, B. R., I. WAgner and J. Kleinschmit (2003): EUFORGEN Technical guidelines for genetic conservation and use for wild apple and pear (Malus sylvestris and Pyrus pyraster), International Plant Genetic Resources Institute, Rome, Italy.

WAGNER, I. (1996): Zusammenstellung morphologischer Merkmale und ihrer Ausprägungen zur Unterscheidung von Wild- und Kulturformen des Apfel- (Malus) und des Birnbaumes (Pyrus). Mitt. Dtsch. Dendr. Ges. 82, 87-108.

Wagner, I., H. P. Schmitt, W. D. Maurer and U. TABel (2004): Isozyme polymorphism and genetic structure of Malus sylvestris (L.) Mill. native in western areas of Germany with respect to Malus x domestica Borkh., Acta Hort. 663, 545-550. 